\title{
Adaptive E-Learning as a Possible Solution to Counter Heterogeneity in Classrooms ? English Grammar Seen Through Cognitive Psychology and Psychometric Methods
}

Julie Villessèche

Julie Villessèche est docteure en études anglophones. Elle est ingénieure de recherche (post-doctorat) à l'université Rennes 2 dans le cadre du projet Tacit-Grammar, en partenariat avec les laboratoires ACE (anglophonie, communautés et écritures) et LP3C (Laboratoire de Psychologie, Cognition, Comportement, Communication).

julie.villesseche@gmail.com

Sandrine Oriez

Sandrine Oriez est professeur en linguistique anglaise à l'Université Rennes 2, et membre de l'équipe de recherche ACE (anglophonie, communauté, écriture). Ses travaux portent sur la syntaxe de l'anglais, la linguistique énonciative et la didactique des langues.

sandrine.oriez@univ-rennes2.fr

Anne-Laure Besnard

Anne-Laure Besnard est mâ̂tre de conférences en linguistique anglaise à l'université Rennes 2, et membre de l'équipe de recherche $\mathrm{ACE}$ (anglophonie, communauté, écriture). Ses travaux en linguistique énonciative portent sur la grammaire de l'anglais (en particulier l'expression de la modalité) et la représentation des points de vue dans le discours journalistique. anne-laure. besnard@univ-rennes2.fr

Olivier Le Bohec

Olivier Le Bohec est mâ̂tre de conférences à l'université Rennes 2, membre du LP3C (laboratoire de Psychologie, Cognition, Comportement, Communication) et co-créateur de la plateforme Tacit. Il s'intéresse à la psychologie de l'éducation, aux recherches et outils concernant l'apprentissage adaptatif en ligne.

olivier.lebohec@univ-rennes2.fr

Christophe Quaireau

Christophe Quaireau est mâ̂tre de conférences en psychologie expérimentale à l'université Rennes 2, membre du laboratoire de Psychologie, Cognition, Comportement, Communication (LP3C) et cocréateur de la plateforme Tacit. Il s'intéresse au rôle de la mémoire et de l'attention dans les apprentissages réalisés à 
l'aide de dispositifs numériques.

christophe.quaireau@univ-rennes2.fr

Yvonnick Noël

Yvonnick Noël est mâ̂tre de conférences en psychologie statistique à l'université Rennes 2, membre du LP3C (laboratoire de Psychologie, Cognition, Comportement, Communication) et cocréateur de la plateforme Tacit. Il est spécialisé dans les modèles statistiques d'analyse des réponses aux tests et questionnaires psychologiques, ainsi que les modèles statistiques de l'apprentissage par renforcement. yvonnick.noel@univ-rennes2.fr

Fanny De La Haye

Fanny De La Haye est mâtere de conférences en psychologie cognitive à l'ESPE de Bretagne, membre du laboratoire de Psychologie, Cognition, Comportement, Communication (LP3C) et cocréatrice de la plateforme Tacit. Elle s'intéresse aux processus cognitifs mis en jeu dans les apprentissages scolaires ainsi qu'à la manière d'améliorer les compétences d'élèves en difficulté. fanny.de-la-hayedespe-bretagne.fr

Jérémie Nogues

Jérémie Nogues est ingénieur d'études à l'université Rennes 2 . Il est le développeur de la plateforme Tacit. jeremie.nogues@univ-rennes2.fr

Karine Lavandier

Karine Lavandier est orthophoniste et co-créatrice de la plateforme Tacit. karine-lavandier@wanadoo.fr

en

One of the main difficulties met in teaching Languages for Specialists of Other Disciplines (Lansod) is the heterogeneity of the learners' levels. Handling a classroom is thus a challenge for teachers. In English, the improvement of both expression and comprehension competences, both written and spoken, depends on the knowledge of grammar, as shown by Ellis's research (Second Language Acquisition). The project presented in this text (TACITGrammar) is part of the dynamic created in the universities in order to develop the use of digital technologies. The platform Tacit targets the evaluation and adaptive remediation of crossdisciplinary cognitive and linguistic competences. In this context, a module dedicated to English grammar is currently in progress to meet the specific needs of the Lansod ${ }^{1}$.

${ }^{1}$ This research was presented at the 2017 RANACLES conference (23-25 November, University of Corsica, Corte). See Quaireau et al. and Villessèche et al. for presentations of the TACIT platform and the Ortho and Implicit modules. 


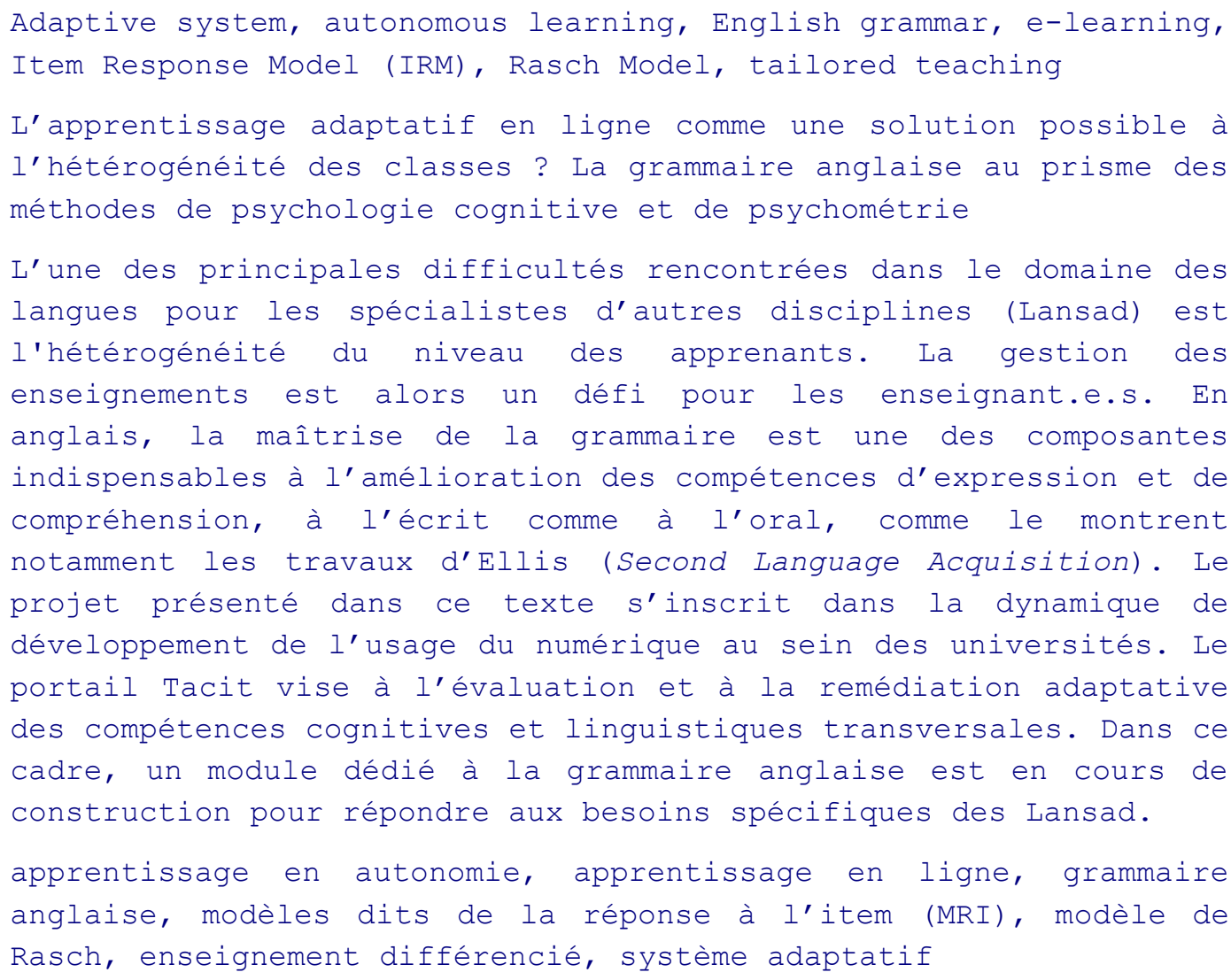

\section{Introduction : Adaptive e-learning}

$21^{\text {st }}$ century teaching has progressively witnessed slow but steady transformations of the classroom, especially with the rapid development and diffusion of the Internet and its related technologies - starting with desktop computers, quickly followed by laptops and smartphones. The latter two have increased the possibilities in terms of both teaching and learning with the growth of online classes and tools, complementing teaching on site. Uniting URL (Uniform Resource Locator) and IRL (In Real Life) is still the ideal a great number of universities are trying to reach.

Languages, as many other disciplines, have benefited from the arrival of these new tools, which have become common in the university curriculum of most students: online dictionaries, tests, exercises, smartphone applications, etc. They have also challenged the way universities or even classrooms work : the list could probably be longer, but to quote just a few - changes occurred with the creation of so-called IT (Information Technology) rooms to give students the opportunity to use computers on campus, with the integration of personal laptops or smartphones in the classroom, but also with the introduction of rules restricting the use of smartphones during exams.

Besides, teachers and students are given new opportunities in terms of class organisation (MOOC - Massive Open Online Course, interactive classroom presentation, etc.) and activities (online exchanges, Skype, etc.). So there is a general movement nowadays for the improvement of the use of digital tools in universities. Thus, for languages, as for many other 
disciplines, the development of those IT rooms and tools has had quite a positive effect on the teacher/student relationship and as a consequence, on the interaction between teaching and learning (see part 2). The idea, as noted earlier, is neither to give the student full autonomy nor to imagine completely virtual teachers, but rather to create tools which will allow teachers to create individual curricula for students. The programs of most French universities, however, do not leave much room for individual follow-up as there is a lack of time, often also linked to a lack of funds, and all this can be coupled with difficulties inherent to Lansod ${ }^{2}$ - i.e. a frequent turn-over among teachers who often hold temporary positions. This is why the development of innovative digital tools has become so crucial: efficient digital tools, such as adaptive systems, are relatively inexpensive individualized solutions providing enhanced learning.

Studies investigating individualized curricula have proved their superiority in terms of learners' performance because those systems solve the problem of the "one-size-fits-all" approach (Vandewaetere et al.). Though those systems are difficult to implement - for the reasons mentioned above - their effectiveness encourages researchers to keep investigating that question. Bloom (4) called it the " 2 sigma problem": "the most striking of the findings is that under the best learning conditions we can devise (tutoring), the average student is 2 sigma above the average control student taught under conventional group methods of instruction". Hence, the researchers' aim is to attain the same results which can be achieved through tutoring, while reducing the cost of this method.

So the question is : what solution can we offer teachers in order to know the level of each of their students and provide students with individual help? In the next two parts, we will further develop the reasons prompting the use of tailored systems within a Lansod context. Then, we will describe the theoretical background which helped build the module. And in the last section, we will present the module per se.

\section{E-learning and tailored systems}

The use of e-learning was demonstrated to be effective as early as the 1980s. Indeed, Bangert et al. showed a general failure of individualized systems based on a meta-analysis of 51 studies but underlined the fact that computer-based systems produced better learning, because they guide students from one level of difficulty to another (153). Computer-based systems may also play a role in terms of motivation : programs which offer a variety of exercises of adequate difficulty with quick feedback (following the recommendations of the American Psychological Association - the APA - to enhance teaching and learning) tend to keep students interested and encourage them to continue. Thus, this study shows that individualized systems do not mean leaving students on their own, but providing educational

\footnotetext{
${ }^{2}$ Languages for Specialists of Other Disciplines (Van der Yeught), translation of the French acronym Lansad originally proposed by Michel Perrin.
} 
support for each student : students are given the opportunity to follow a course in a one-toone configuration in the same way as with tutoring; the pace of the teaching process is thus adapted to the pace of the learner. This is the principle of a tailored system.

There is one form of tailored systems which goes even further in the sense that it matches not only the pace of the learners but also their level of competence : it is called adaptive elearning. The core of an adaptive system is individual performance. Such systems have been established as effective in several studies, such as Di Giacomo et al., Truong, Yang et al.

There are different levels of possible adaptations : adaptive systems can be tailored content, presentation, tools, they can take into account individual preferences or knowledge, they can give personal objectives, etc. Here, we are interested in the relation between individual performance and item difficulty. Several possibilities are available to adapt content and instruction to the learners' needs and characteristics. Vandewaetere et al. (119) identify three types of instructions : (a) macro-adaptive instruction, (b) aptitude-treatment interaction, (c) micro-adaptive instruction. The first approach corresponds to mastery learning; the second one is a more comprehensive approach, which takes into account learners' personal characteristics such as anxiety. For example, anxious students prefer structured systems of instructions. Mödritscher et al. (2) underline the fact that it is better to give fixed tasks so as to limit the possibilities of control by the students, especially for those "with low-prior knowledge" regarding the pace of the task, for example.

The last type, micro-adaptive instruction, is the one which corresponds to our research here : it "diagnoses learner's specific learning needs during instruction and subsequently provides appropriate instructional prescription for these needs" (Vandewaetere et al. 119). It is a dynamic model, which can fit into a classroom environment. It extends the possibilities of a teacher-learner interaction through an online tutoring system. Consequently, the teacher can follow the individual progress of each student, creating the environment needed for blended learning (Kakosimos). The principle is that on the one hand, each student is provided with content adapted to their needs, while teachers can provide feedback individually or to groups of students and on the other hand, the system does not need any external intervention - such as teachers selecting exercises - to provide the content environment which fits each student's abilities. Of course, the system, like the one we will present later, can sometimes leave the possibility of external intervention to take into account motivational factors for example. Thus, in this case, the clear matching of the level of competence of the learners with the difficulty level of the exercises allows the teachers to easily select, via the interface, the level of difficulty of the items. These items, for example, will be chosen from a student's area of competence or a slightly higher area (see the classic notion of a proximal zone of development, Vygotski 270), or in a lower zone to put the learner in a motivating situation of success. These possibilities of choice allow concrete individualized remedies and facilitate the management of the heterogeneity of skills within the same class. 


\section{Adaptive e-learning environment use in a Lansod}

Teachers in Lansod are confronted to the high heterogeneity of students, especially if the class groups are based on the faculty where the student is registered and not on their level of competence for languages. So, generally, a same class group is made of students following different course pathways at university and who do not have the same level. For their main second language, students are supposed to have a B2 level after the baccalauréat (K-12 national examination). But this is not generally the case and this level is far from being acquired. In France, this heterogeneity is difficult to handle as the average number of language course hours in Lansod is about two hours a week, and because of a lack of staff, some universities have even turned toward alternative systems such as two intensive weeks per semester, one at the beginning and one at the end, which makes it difficult to handle heterogeneous levels, especially if, as mentioned above, groups are not based on students' competences. In this case, the rest of the semester leaves students with full autonomy, with means to support this autonomy which vary from one university to another. Thus, with this short amount of time allocated to second languages, the time to revise grammatical bases is generally very limited.

Besides, creating homogeneous groups requires time and equipment. Creating online tests means students will need computers to take the tests : the number of students makes it very difficult to organize. Some solutions are proposed : for example, when students register at home, they are required to take a test in order to choose the group where they will best fit in. However, such a system depends on the students' honesty for the test (no other material than the test itself should be used, such as dictionaries, or grammar assistance) and therefore, for the choice of a group. The choice of tests also varies from one university to another (Brudermann et al.).

But adaptive e-learning is a means to create individualized tailored systems - as seen previously - so it is at the same time a pedagogical and research tool, in the sense that it gives teachers and researchers access to a great deal of data, which, in pedagogical terms, enables teachers to know more precisely the level of each student, and possibly, to create smaller groups within the classroom according to levels of competence. Such a system is a possible answer to the problem of heterogeneous classes, when organising students according to their levels cannot be done before the beginning of the semester.

Indeed, it can either be used as a support system outside the classroom thanks to the adaptive module, or as a means of setting up smaller groups depending on the students' levels within the classroom. It also enables students to obtain individual help to strengthen the bases they may not have acquired before registering at the university and it does not add more constraints to the teachers' tasks, as the system determines the students' level without any external intervention. 
Hence, an adaptive e-learning platform seems to be a potential solution to help solve the difficulties generated by the heterogeneity of groups and the lack of time induced by a limited number of hours of in-class teaching/learning.

\section{Methodology : an English grammar module based on an explicit approach}

In France, for decades, grammar teaching was the fundamental basis when learning a foreign language (Puren), contrary to English-speaking countries where teachers and researchers favoured language practice over teaching grammar rules very early on. The latter approach was rooted in the comparison between first and second language acquisition: as native speakers do not need grammar lessons to speak their mother tongue, second language learners could acquire grammar in the same way - i.e. linguistic immersion (Kraschen "Second Language Acquisition"). Therefore, for a very long time, the unconscious and implicit acquisition of the grammatical competence was favoured by the "Anglophone method", while a conscious and explicit approach of grammar was preferred by the "French method".

However, the advent of the CEFRL (Common European Framework of Reference for Languages) and the definitions of levels common to every language progressively changed the way languages were taught, even in France. The problem of the conscious and explicit approach to grammar was the way it was taught at the time (until the 1970s) : the most popular method was structural exercises or drills. And, as Newby (13) puts it,

\footnotetext{
since learners are presented with pre-fabricated sentences, processing is limited to applying a rule deductively and is, as a result, very shallow. The fact that so much language is provided precludes the need for or the possibility of schematization. Such exercises are, of course, fairly boring and satisfy neither cognitive nor affective needs. Commitment is therefore likely to be low. (Newby 13)
}

What the CEFRL has brought is a new approach based on action-oriented tasks. The principal aim is communication, and it is enhanced by the integration of the interlanguage (Selinker). This interlanguage is considered to be part of the learners' competences, which are the linguistic, the sociolinguistic and the pragmatic competences. So when it comes to evaluation, the idea is to insist on what the learner can write and say, instead of insisting on the importance of using the language properly. The system, centred on the actions and competences of the learner, necessarily puts aside grammatical questions - not in the sense that grammar is not supposed to be taught, but mistakes are only corrected when the learner makes them, and they are not anticipated by specific grammar lessons. This was meant to avoid heavy grammar teaching, which has been proved demotivating for students (Freinet ; Falout et al.). For that reason, in this situation, one may question the relevance of reintroducing grammar through a module entirely dedicated to it. 


\title{
4.1. Reintroducing grammar as an independent variable
}

As we pointed out earlier, the question is not really whether or not grammar should be taught but rather: what kind of grammar teaching should be implemented ? Should it be explicit or implicit?

The action-based approach is built on the naturalistic point of view in L2 acquisition research. This idea, argued by researchers such as (Corder "The Significance"; Krashen "Second Language Acquisition" or Ellis "Current Issues") is that

\begin{abstract}
learners appeared to follow a natural order and sequence of acquisition (i.e. they mastered different grammatical structures in a relatively fixed and universal order and they passed through a sequence of stages of acquisition on route to mastering each grammatical structure (Ellis "Current Issues" 85).
\end{abstract}

In this configuration, instructed learners (or classroom learners) like naturalistic ones are supposed to follow the same inner syllabus. They are supposed to acquire grammatical structures when they access them through different types of natural input. Different attempts were made in this direction : some supposed the teaching of grammar structures should follow the same pattern as natural grammar acquisition (for example, Pica); others (Krashen "Principles") thought that input should be limited to simple structures as complex ones were too difficult to acquire in instructed situations.

However, more recent research (Ellis "Language Teaching", Spada and Tomita) has shown that evidence supports explicit grammar teaching. Indeed, those opposite claims argue that implicit teaching cannot suffice when dealing with complex structures (Hulstijn and de Graaff), especially because those structures occur less frequently in natural discourse. So natural input is not enough for them to be noticed. Another argument in favour of explicit grammar teaching is the necessity for the learner to be able to access grammatical knowledge with ease in order to fulfil instantaneous and fluent communication as, according to Ellis (“Current Issues" 97),

\footnotetext{
explicit knowledge can convert into implicit knowledge if the learner is ready to acquire the targeted feature and that this conversion occurs by priming a number of key acquisitional processes, in particular noticing and noticing the gap (Schmidt, 1990). That is, explicit knowledge of a grammatical structure makes it more likely that learners will attend to the structure in the input and carry out the cognitive comparison between what they observe in the input and their own output. (Ellis "Current Issues" 97)
}

Since then, the benefits of explicit grammar teaching have been shown by a large amount of research (Ellis "Language Teaching"). They show that the learners who follow courses including explicit grammar teaching learn faster and reach a higher level than the learners who do not have access to such courses. Thus explicit teaching favours the acquisition of a language, allowing the learner to be conscious of their own mistakes and to correct them. 
Besides, the automatisation of explicit knowledge helps students learn grammatical forms progressively (DeKeyser) and it also favours the implicit knowledge of grammar (Lantolf and Thorne). This question of automatisation of explicit knowledge targets a specific problem : what kind of exercises can tackle the automatisation of explicit knowledge ?

\subsection{Multiple-choice tests as an effective adaptive solution?}

We established earlier that an adaptive e-learning platform was a possible solution to help teachers deal with the heterogeneity of student groups. Such a system has some constraints : the main one is to make sure that the answers provided by the students are indeed a reflection of what they have learned, i.e. are not influenced by the format of the questions in a way that would impede the learning process. To the best of our knowledge, there are two solutions to deal with that problem.

One of them is to use open fields for answers, but for some exercises, there could be several correct answers, which means that they all need to be recognized as such. Though this system might seem ideal, it is extremely costly in terms of time concerning the creation of the exercises but also concerning the calibration of the exercises (i.e. classifying from the easiest to the most difficult). Indeed, an adaptive system means that the student's level of competence can be known because the exercises have been calibrated. In order to carry out this classification, the exercises must have been submitted to a great number of students in the first place. In a fixed amount of time, the number of exercises completed by students is generally less important when they have to write a full answer and not just pick one. This leaves us with the second solution.

The second way to deal with the numerous different answers students may give is multiplechoice questions (Figure 1).

Figure 1. Screenshot of TACIT showing an example of a finalized MCQ exercise in the category "Translate the conditional" 


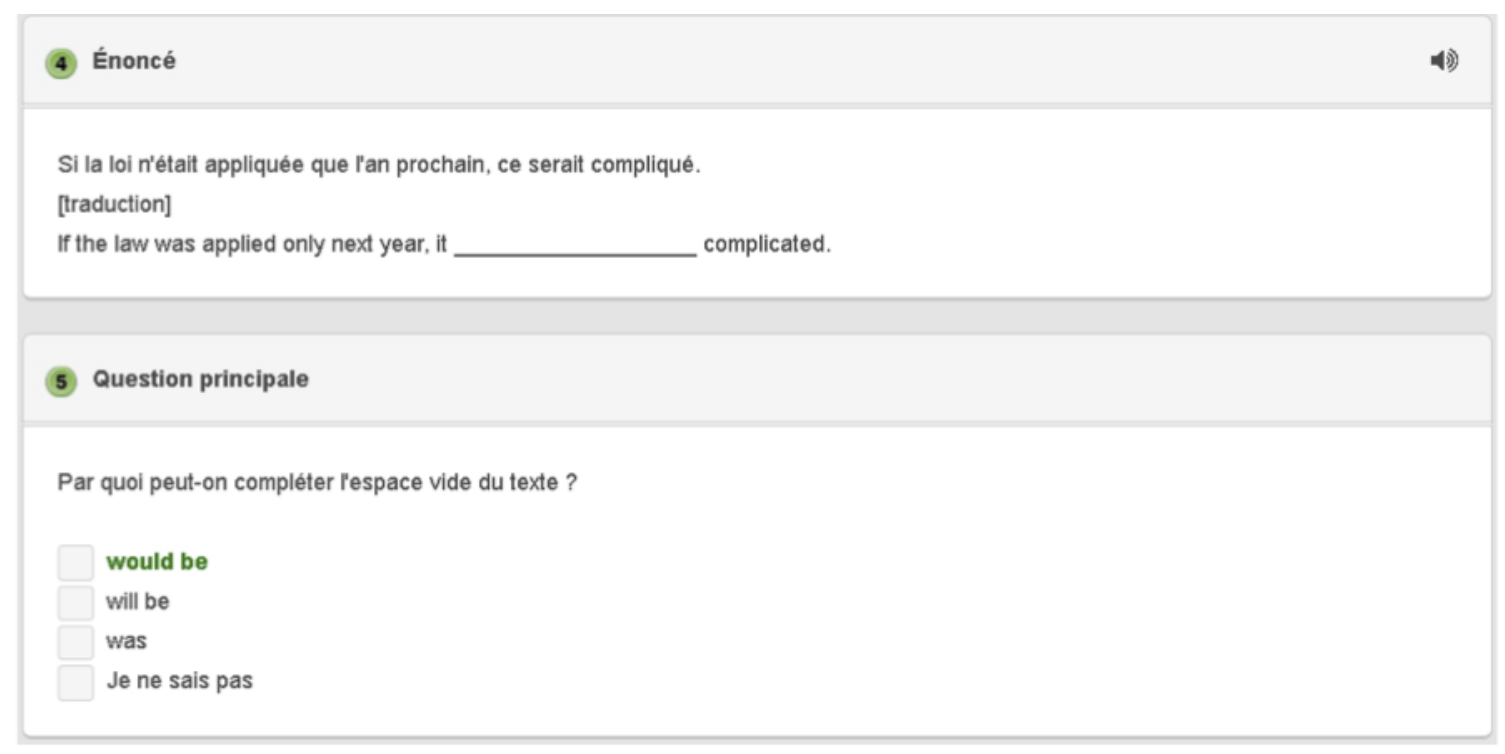

It offers several advantages : (a) it allows the reduction of the number of possible answers ; (b) it increases the number of exercises which a student may answer in a fixed amount of time - this also has a practical research advantage as it is less time consuming when submitting the exercises to the students in order to determine the difficulty of the exercises (i.e. calibration) ; (c) it enables the creation of an adaptive system using the IRM (Item Response Models), in this case the Rasch Model (see 5. for more explanations); (d) Multiple-Choice Questions (MCQ) used as pedagogical tools and not as tests have been proved effective as they play a role of external monitoring for learners, who tend to overestimate their level of competence in situations of self-assessment (Koriat and Bjork).

\subsubsection{Multiple-choice questions : a 'drill and kill' method?}

The problem of multiple-choice tests is that they are associated to the 'drill and kill' method, which consists in trying to create automatisation of grammatical structures through repetition. Here, the multiple-choice tests are based on the form recommended by Khodamoradi and Khaki. The exercises must have meaning and should be based on the will to say something, not on the structures, which would only lead to check the knowledge of a grammatical form. The solution we have chosen to avoid a 'drill and kill' practice is based on two axes : first of all, grammatical structures are embedded in context ; secondly, all exercises are translated.

The main reason justifying the use of translation here is to shift the focus from the form to the meaning; another aim is to keep learners motivated, providing them with a pool of repeated opportunities to practice and succeed (translation maximizes opportunities for success by bypassing capacity limits of working memory and helping attention guidance toward the grammatical aspects). And, as authors such as Cook or Ellis ("A Theory") showed, the first language (L1) is a resource for learners trying to acquire a second language (L2). Widdowson (152) even underlines that learning a language is a bilingual experience, and that, whatever the method, learners keep going back and forth between their L1 and L2 in their minds. 
Furthermore, Hall (73) argues that L1 can also be a resource for the teacher, for explanations or in order to underline differences or similarities between languages. So translation is both a resource for learners to deal with those exercises, and it is also a means to fulfil a particular goal on the platform: the problem here is to be able to evaluate learners' competence in grammar, not in comprehension; so translating the exercises is a way of isolating the evaluation of this particular competence.

\subsubsection{Multiple-choice questions : methodology}

Multiple-choice questions have been proved effective both in the case of learning (Roediger and Marsh ; Butler et al. "The Effect") and more precisely in the case of language acquisition (Khodamoradi and Khaki ; Hemmati and Ghaderi). Multiple-choice questions have benefits in terms of retention both in the short and long terms. The main problem of that retention of tested information is that, in the case of learners who choose a wrong answer, there also is possible retention of that incorrect information (Little and Bjork). This is mitigated by the number of options submitted to the learner for each question :

$$
\begin{aligned}
& \text { increased numbers of similar lures on multiple-choice tests can impair participants' } \\
& \text { performance on the multiple-choice test and general knowledge as assessed on a } \\
& \text { later cued recall test. (Butler et al. "When" 954) }
\end{aligned}
$$

So, in terms of methodology to choose a format for those multiple-choice questions, there were two problems to solve : (a) how to avoid the retention of incorrect information ; (b) how many lures should be used.

In the case of the retention of incorrect information, Butler and Roediger proposed a solution : feedback. Indeed, Pashler, et al. tested this question and came to the following conclusion : the effectiveness of the MCQ is considerably enhanced if the correct answer is given (i.e. telling the learner that their answer is incorrect is not enough, a correction is needed as a complement). They also concluded that feedback does not have a significant impact if the learners gave the correct answer. However, if they chose the wrong answer, the feedback had, on the contrary, a particularly significant effect. The study of Butler and Roediger (611-612) confirms those conclusions and also shows that if information has been tested a first time, the learners' results are better the second time whatever the form of the test (whether MCQ or free recall test).

The second question, which is also related to the problem of learners memorising incorrect information, is about lures. How many options should we give learners ? And what kind of options? The number of lures is above all related to the general use of MCQ : they are generally used for tests and less as a pedagogical tool. Many studies such as Frary, Haladyna, et al., Burton ("Reliability Measures" and "Myths" or Vegada et al. "Comparison" try to find measures to prevent students from guessing and to make MCQ as efficient as possible - i.e. MCQ should make it possible to rank students. So what they generally propose is the increase of the number of lures per question, or putting in place negative marking, etc. But, as stated 
by Butler et al., increasing the number of options given to learners also increases the possibility of retention of incorrect information. Moreover, Haladyna and Downing have shown that it is very difficult to increase the number of lures while maintaining the credibility of the lures. Hence they advised, as Burton ("Quantifying"), that the focus should be kept on the quality of lures and that three or four lures - these numbers include the correct answer are a good limit to keep in mind.

These reflexions are the backbone of the module we have created. The next part will present the result - the English grammar module - but also the possibilities this module offers in terms of teacher-learner relations. Indeed, the creation of such a tool is entangled with the needs of Lansod, which must address the heterogeneity of student groups without increasing the costs in terms of staff, budget or time.

\section{Result : the TACIT-Grammar module}

The TACIT (Testing adaptatif des compétences individuelles transversales) platform which will support the English grammar module is already online and accessible from any browser, as a first module for enhancing the comprehension of implicit information in French texts was launched in 2012 and another in 2014 with a focus on French vocabulary. The platform is divided between a part aimed at being used by speech therapists, and another one intended for the classroom. So far, it has been used by primary and secondary schools.

In 2013, a project was born, from a collaboration between two research teams, TACIT mainly composed of researchers from the LP3C (Laboratoire de psychologie : cognition, comportement, communication) and ACE (Anglophonie : communautés et écritures), both in the university Rennes 2 . The collaboration was then extended to the Lansod of that university. The module offers two modalities : a synchronous one (for use in the classroom) and an asynchronous one (for autonomous use). This module can thus be used to create blendedlearning-type courses. It enables teachers to have precise and genuine progress indicators for each of their students.

Earlier, we gave the reason that drove us to choose multiple-choice questions over other types of exercises (2.2.2) - including their effectiveness and compatibility with IRM (here, Rasch Model). The IRM are statistical models which allow the adaptive system to represent both the learners' level of competence and the level of difficulty of the exercises on the same continuum. Though they are not used very much in applied psychometrics in France, they enable researchers to create adaptive pedagogical systems, where the exercises are selected according to the learner's level of competence. The model which was used here is the Rasch model :

The examiner can use the target person's performance on such a variable segment of self-chosen items to estimate his ability [...], the process is self-tailoring. As the target person takes the test he finds for himself the items in the test booklet of difficulty best for him. (Wright and Douglas 2) 
We have also sided with conclusions which favour the quality over the quantity of options given for each question. That is why the exercises are built in two stages : one to determine the incorrect options given for each question and the other one to evaluate the level of difficulty of each exercise.

In the first stage, exercises are submitted to students, not as MCQ, but as open-field exercises in order to collect incorrect answers produced by the learners themselves. This enables us to cover all the strategies which prevent learners from connecting the meaning of a sentence with the correct grammatical form. Then, the incorrect answers are chosen according to three criteria: if they are the most frequently used, if they fit in terms of quality (spelling, vocabulary, etc.) and if they correspond to erroneous strategies (for example, if the incorrect answer given is a calque). In this stage, the learners are given one possible good answer after they validate their own answer. The exercises thus submitted are in their final form, in the sense that the translation associated is already there. See Figures 2 and 3.

Figure 2. Screenshot of TACIT showing an example of an unfinalized $M C Q$ exercise on the passive 
Ses peintures se sont bien vendues, principalement achetées par des proches. [traduction]

Her paintings sold well, family and friends.

(5) Question principale

Par quoi peut-on completer l'espace vide du teste ?

mostly bought by

Je ne sais pas

\& Liste des réponses données pour cet exercice

() Mainly bought by (16.67\%, 3 élèves)

() Mostly bought by (16.67\%, 3 éleves)

() Mostly buying (5.56\%, 1 élève)

○ Principly by her (5.56\%, 1 elève)

() Mostly bought from (5.56\%, 1 elève)

( ) Pricipaly buy (5.5696, 1 eleive)

○ Jene sais pas (5.56\%, 1 élève)

( ) Generaly bought by ( $5.56 \%$, 1 elève)

() Mostly bought (5.56\%, 1 elève)

○ Buyfor (5.56\%, 1 elève)

(- Principaly buy of $(5.56 \%, 1$ elève)

○ Buight (5.56\%, 1 elève)

○ Principaly bought by (5.56\%, 1 élève)

○ Mainly by (5.56\%, 1 elève)

Figure 3. Screenshot of TACIT showing an example of an unfinalized $M C Q$ exercise on the expression of concession and contrast 


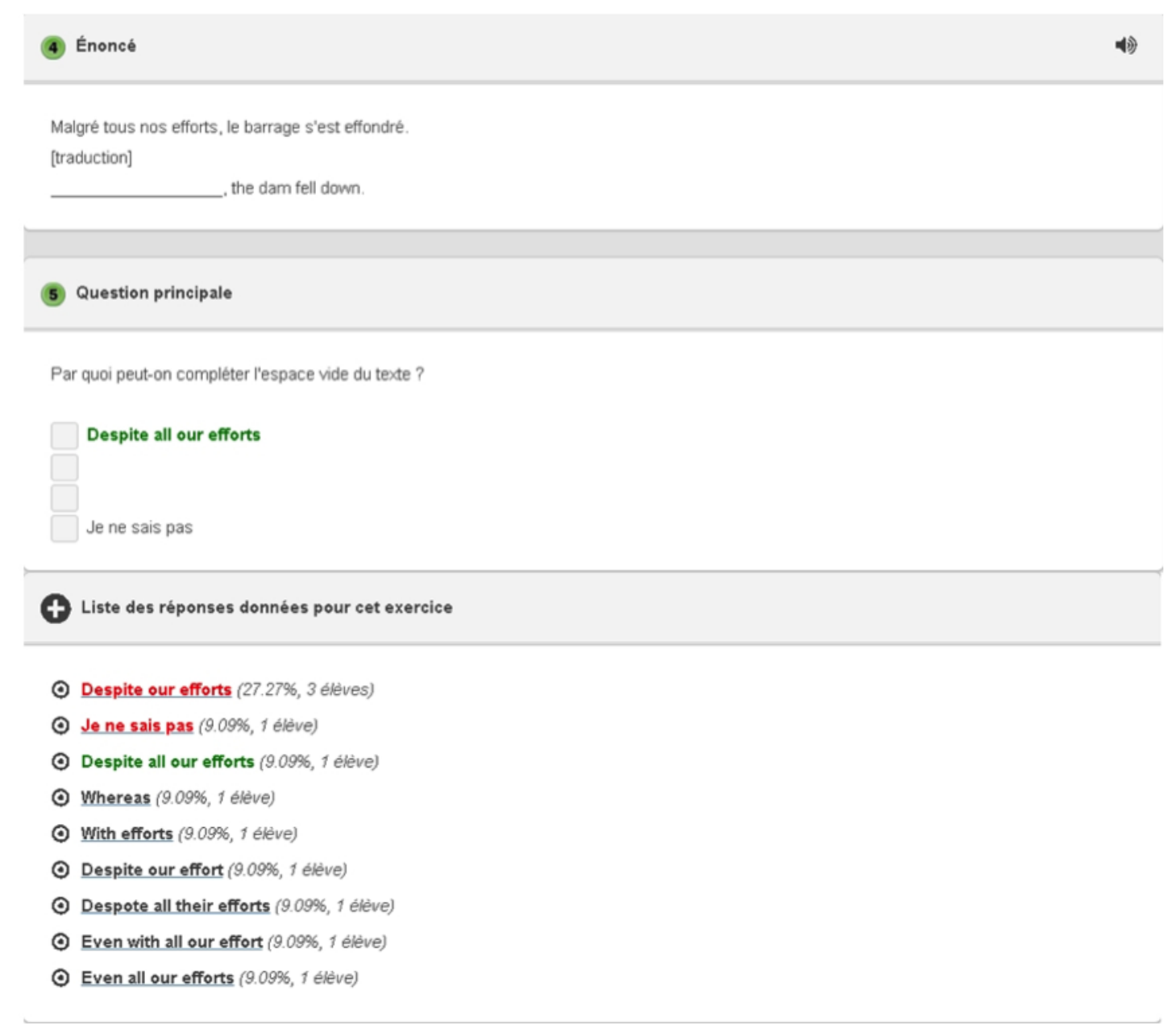

In the second stage, the exercises are now in an MCQ form. The purpose is to evaluate the level of difficulty of the exercises in order to be able to match this level of difficulty with a level of competence, which can then be attributed to each learner. The ranking of the exercises follows the IRM. In this case, the experience takes the form of a test : the learners do not know if the answer they have given is correct or incorrect. This measure is taken to avoid a possible learning effect during the test. This stage is completed once we have enough material to prepare five evaluations of 20 exercises - those exercises are the ones which reach the gold standard according to the IRM. The rest of the exercises are used for practice. To be finalised, the exercises have to be submitted to a great number of learners : each exercise has to be completed at least 120 times.

The base is composed of almost ten thousand exercises, which have been divided into 52 grammatical categories. The categories can be regrouped into three types : noun phrase (1824 exercises, $19.21 \%$ ), verb phrase (4183 exercises, $44.06 \%$ ) and syntax of the sentence (3486 exercises, $36.72 \%$ ). The purpose was to cover as many grammatical forms as possible while also creating categories based on difficulties often met by students : for example, translating the future or managing "the syntax of the sentence" (Figure 4). 


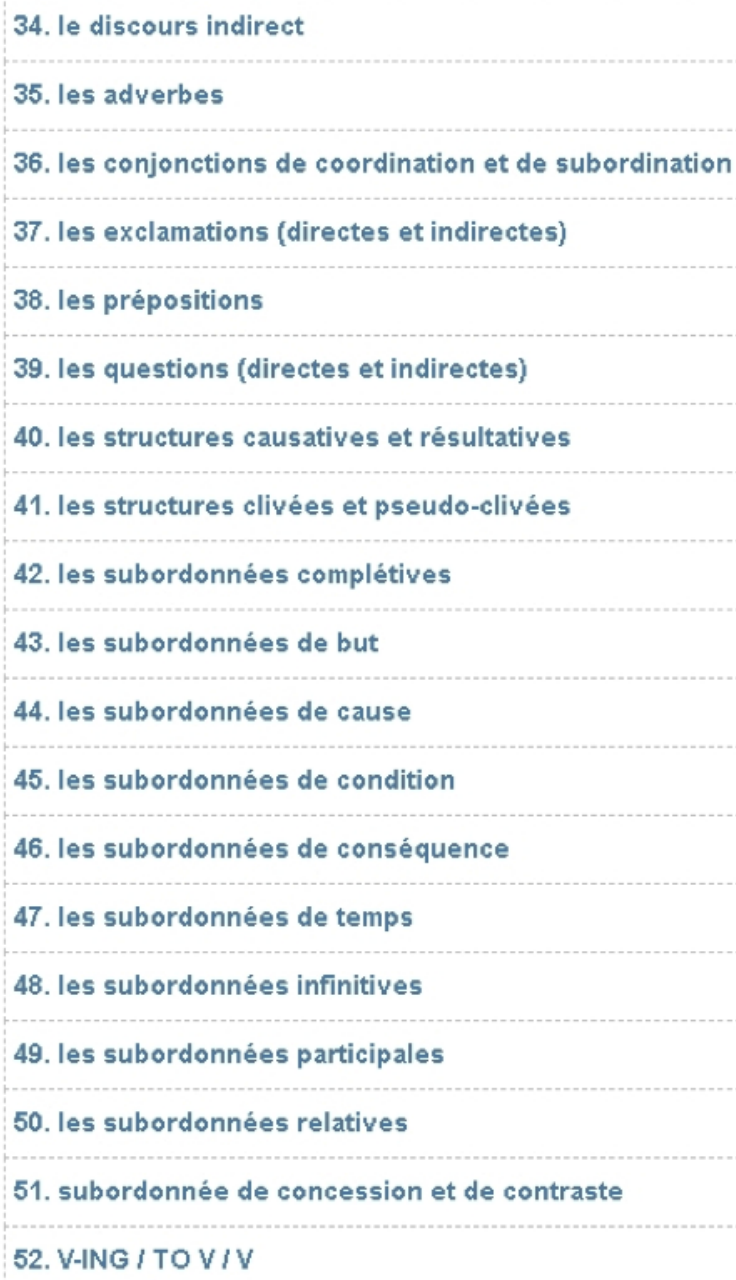

So far, more than 3,500 exercises have already gone through the first stage, and are in MCQ form. We are currently completing the first stage, collecting the most interesting incorrect answers for each unfinalized exercise (as shown in Figures 2 and 3 above). We hope that the module will be ready in 2019 .

Once completed, TACIT-grammar will offer two possibilities :

- In-class use will be based on the same parameters which already exist on the platform for two other modules : Implicit comprehension and Vocabulary (in French). In this case, learners start with an evaluation of 20 exercises. This evaluation places the learner on a competence scale. Then, the exercises presented to the learner match the learner's competence in terms of difficulty. Learners have to take another evaluation in order to re-evaluate their level and see their progress. In this case, the platform provides teachers with visual summaries of the learners' history for the module and progress. The teacher may give homework to the learners - TACIT-grammar exercises automatically distributed according to the learners' level. In this situation, the teacher 
is provided with all the information : they neither have to select the exercises nor define their learners' competence level.

- Use in autonomy: This time, the system is entirely adaptive, which means that after a first exercise is proposed to the learners, the system then adapts the exercises given to the learners according to their achievements or failures (Quaireau et al. 4).

This means that the module is built to circumvent the heterogeneity of the classroom, in the sense that teachers do not have to find ways to monitor their learners' competence level, and learners are not given random exercises which would not specifically match their competence level.

\section{Discussion}

We have seen to what extent grammar is essential to the development of English competences, both written and spoken. A lot of learners arrive at university with difficulties they have accumulated over time : they did not manage to develop their grammar competence during their secondary school curriculum and they need further help, which often cannot be provided for lack of time, staff and budget. One element of solution can come from the proven efficiency of blended learning, with face-to-face courses coupled with (adaptive) elearning tools. Indeed, a systematic search of the research literature from 1996 through July 2008, prepared for the U.S. Department of Education, identified more than a thousand empirical studies on online learning. One of the most interesting results is that "Instruction combining online and face-to-face elements had a larger advantage relative to purely face-toface instruction than did purely online instruction" (U.S. Department of Education,17).

Functional since 2012 , with now about 85,000 primary or secondary school students working on L1 French, the TACIT adaptive e-learning platform may also benefit university students learning L2, both in face-to-face situations and in distant e-learning.

In face-to-face interaction, it is much easier for teachers to help each non-self-regulated learner (Zimmerman) to begin their learning with the forethought phase (i.e. careful consideration of what will be necessary to succeed in learning; task analysis, strategic planning, goal setting). They can also help learners to become more autonomous, to procrastinate less often, to develop different strategies that can make learning "easier, faster, more enjoyable, more self-directed, more effective, and more transferable to new situations" (Oxford 8). Nevertheless, simply telling students that they need to develop different learning strategies to progress in L2 and to earn good grades will not usually lead to develop autonomy and motivation. Still,

it is important to teach students that some tasks, even tasks that are necessary to master, might be uninteresting at first yet require consistent, sometimes tedious, engagement for learning. Once learned, new skills may become their own reward. (APA 22) 
Another important point needs to be noted : to pursue L2 learning, at university, is less often "adding to existing student knowledge, known as conceptual growth", and more often "transforming or revising student knowledge, known as conceptual change" (APA 7). Teachers can be instrumental in achieving conceptual change in students, for example in L2 grammar acquisition, by using tools

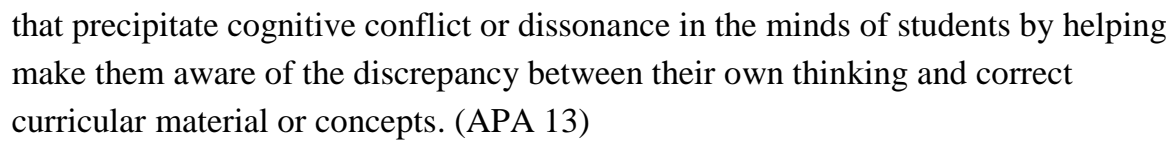

The English grammar module was built to help both learners and teachers in this task. Indeed, in addition to the own-pace training mode, the TACIT platform integrates a tutored training mode. This second mode allows the teacher to conduct training sessions by introducing phases of interaction and explanation of the exercises encountered. Tutored training makes it possible to take into account the heterogeneity of the levels of knowledge ${ }^{3}$ and also the misconceptions that "tend to be entrenched in reasoning and resistant to change" (APA 13). A very large set of exercises is needed for this conceptual change to take place, which is why the Tacit-grammar module requires about 9,500 various exercises.

What has been presented here is the background of a new adaptive-system module created for students and teachers within the university Rennes 2. Both MCQ and adaptive systems are recognised as valuable and effective pedagogical tools, but they are also both objects of research - which was the purpose of this article, and means of research - which will help to better understand the place of the grammatical competence within learners' overall competence in English.

Indeed, the main objective of the research we are currently conducting using TACIT is to help students make progress, especially those in their first year at university, who have not yet reached a B2 level. The use of the TACIT platform will also make it possible to collect data from those learners and to compare it with their results to other tests (CLES, TOEFL, etc.). In this way, we hope to reach an equilibrium between researchers', teachers' and learners' expectations. The platform should be made available to all universities wishing to sign an agreement with the University of Rennes 2.

\footnotetext{
${ }^{3}$ Acquiring long-term knowledge and skill is largely dependent on practice but this practice needs to be welladapted (neither too easy nor too difficult) to be efficient and motivating. "Providing information that is not too elementary to be easily understood and not too complex to be out of range of understanding even with assistance represents the perfect level of entry for new material" (APA 9). "As students develop increasing competence, the knowledge and skills that have been developed provide a foundation to support the more complex tasks, which become less effortful and more enjoyable. When students have reached this point, learning often becomes its own intrinsic reward" (APA 16).
} 
American Psychological Association, Coalition for Psychology in Schools and Education. Top 20 Principles from Psychology for PreK-12 Teaching and Learning. 2015, www.apa.org/ed/schools/cpse/top-twenty-principles.pdf. Accessed 18 Oct. 2018.

Bangert, Robert L., et al. "Individualized Systems of Instruction in Secondary Schools." Review of Educational Research Summer, vol. 53, no. 2, 1983, pp. 143-158.

Bloom, Benjamin S. "The 2 Sigma Problem : The Search for Methods of Group Instruction as Effective as One-to-One Tutoring.” Educational Researcher, vol. 13, no. 6, 1984, pp. 4-16.

Bonk, Curtis J., and Charles R. Graham. Handbook of Blended Learning: Global Perspectives, Local Designs. San Francisco, CA, Pfeiffer Publishing, 2006.

Brudermann, Cédric, et al. "Le secteur des langues pour spécialistes d'autres disciplines dans les universités françaises : résultats d'une enquête nationale menée par la SAES." Recherche et pratiques pédagogiques en langues de spécialité, vol. 35, no. 1, 2016, pp.1-19, doi: 10.4000/apliut.5564.

Burton, Richard F. "Quantifying the Effects of Chance in Multiple Choice and True/False Tests : Question Selection and Guessing of Answers." Assessment \& Evaluation in Higher Education, vol. 26, no. 1, 2001, pp. 41-50.

---. "Multiple Choice and True/False Tests : Reliability Measures and some Implications of Negative Marking." Assessment \& Evaluation in Higher Education, vol. 29, no. 5, 2004, pp. 585-595.

---. "Multiple-choice and True/False Tests : Myths and Misapprehensions." Assessment \& Evaluation in Higher Education, vol. 30, no. 1, Feb. 2005, pp. 65-72.

Butler, Andrew C., and Henry L. Roediger III. "Feedback Enhances the Positive Effects and Reduces the Negative Effects of Multiple-Choice Testing." Memory \& Cognition, vol. 36, no. 3, 2008, pp. 604-616.

Butler, Andrew C., et al. "When Additional Multiple-Choice Lures Aid versus Hinder Later Memory.” Applied Cognitive Psychology, vol. 20, 2006, pp. 941-956.

Butler Andrew C., et al. "The Effect of Type and Timing of Feedback on Learning from Multiple-Choice Tests." Journal of Experimental Psychology: Applied, vol. 13, no. 4, 2007, pp. 273-281.

Cook, Guy. Translation in Language Teaching : An Argument for Reassessment. Oxford, Oxford University Press, 2010.

Corder, Stephen P. “The Significance of Learners' Errors.” International Review of Applied Linguistics, vol. 5, 1967, pp. 161-169. 
DeKeyser, Robert. "Beyond Focus on Form : Cognitive Perspectives on Learning and Practicing Second Language Grammar." Focus on Form in Classroom Second Language Acquisition, edited by Doughty, C. and J. Williams, Cambridge, Cambridge University Press, 1998, pp. 42-63.

Di Giacomo, Dina, et al. "The Silent Reading Supported by Adaptive Learning Technology : Influence in the Children Outcomes." Computers in Human Behavior, vol. 55, 2016, pp. 1125-1130.

Ellis, Rod. "A Theory of Instructed Second Language Acquisition." Implicit and Explicit Learning of Languages, edited by Ellis, N., San Diego, Academic Press, 1994.

---. Second Language Acquisition. Oxford, Oxford University Press, 1997.

---. "Current Issues in the Teaching of Grammar: An SLA Perspective." TESOL QUARTERLY, vol. 40, no. 1, March 2006, pp. 83-107.

---. Language Teaching Research \& Language Pedagogy. West Sussex, Wiley-Blackwell, 2012.

Falout, Joseph, et al. "Demotivation: Affective States and Learning Outcomes." System, vol. 37, 2009, pp. 403-417.

Frary, Robert. "Formula Scoring of Multiple-Choice Tests (Correction for Guessing)." Educational Measurement : Issues and Practice, Summer 1988, pp. 33-38.

Freinet, Célestin. La méthode naturelle : L'apprentissage de la langue, Cannes, Editions de l'Ecole Moderne Française, 1968.

Haladyna, Thomas M., and Steven M. Downing. "How Many Options is Enough for a Multiple-Choice Test Item ?" Educational and Psychological Measurement, 1993, vol. 53, 1993, pp. 999-1010.

Haladyna, Thomas M., et al. "A Review of Multiple-Choice Item-Writing Guidelines for Classroom Assessment." Applied Measurement in Education, vol. 15, no. 3, 2002, pp. 309333, doi : 10.1207/S15324818AME1503_5.

Hall, Graham. Exploring English Language Teaching : Language in Action, Routledge, 2011.

Hemmati, Fatemeh, and Esmaeil Ghaderi. "The Effect of Four Formats of Multiple-Choice Questions on the Listening Comprehension of EFL Learners." Procedia - Social and Behavioral Sciences, vol. 98, 2014, pp. 637-644.

Hulstijn, J. H., and R. de Graaff. "Under What Conditions Does Explicit Knowledge of a Second Language Facilitate the Acquisition of Implicit Knowledge ? A Research Proposal.” AILA Review, vol. 11, 1994, pp. 97-112. 
Kakosimos, K.E. "Example of a Micro-Adaptive Instruction Methodology for the Improvement of Flipped-Classrooms and Adaptive-Learning Based on Advanced BlendedLearning Tools.” Education for Chemical Engineers, vol. 12, 2015, pp. 1-11.

Khodamoradi, Abolfasz, and Nasrin Khaki. "The Effect of Mechanical and Meaningful Drills on the Acquisition of Comparative and Superlative Adjectives." International Journal of Linguistics, vol. 4, no. 4, 2012, pp. 264-274.

Koriat, Asher, and Robert A. Bjork. "Illusions of Competence in Monitoring One's Knowledge During Study." Journal of Experimental Psychology : Learning, Memory, and Cognition, vol. 31, no. 2, 2005, pp. 187-194.

Krashen, Stephen. Second Language Acquisition and Second Language Learning. Oxford, Oxford University Press, 1981.

---. Principles and Practice in Second Language Acquisition. Oxford, Pergamon, 1982.

Lantolf, James P., and Steven L. Thorne. Sociocultural Theory and the Genesis of Second Language Development. Oxford, Oxford University Press, 2006.

Le Grand, Séverine. "Utilisation de questionnaires collaboratifs et de smartphones en cours de langues.” Présentation, Demi-Journée d'Étude autour des TICE, Université Rennes 1, July 2017.

Michinov, Nicolas, et al. "Procrastination, Participation, and Performance in Online Learning Environments." Computers \& Education, vol. 56, no. 1, 2011, pp. 243-252.

Little, Jeri L., and Elizabeth Ligon Bjork. "The Persisting Benefits of Using Multiple-Choice Tests as Learning Events." Proceedings of the Annual Meeting of the Cognitive Science Society, vol. 34, 2012, pp. 683-688.

Mödritscher, Felix, et al. "The Past, the Present and the Future of Adaptive E-learning." Proceedings of International Conference of Interactive Computer Aided Learning (ICL), Villach, Austria, 2004.

Newby, David. "Do Grammar Exercises Help? Assessing the Effectiveness of Grammar Pedagogy." ELT Harmony and Diversity, edited by Haase, Christoph, and Natalia Orlova, Newcastle upon Thyne, Cambridge Scholar Publishing, 2014, pp. 3-16.

Oxford, Rebecca L. Language Learning Strategies : What Every Teacher Should Know. New York, Newbury House/Harper \& Row, 1990.

Pashler, Harold, et al. "When Does Feedback Facilitate Learning of Words ?" Journal of Experimental Psychology : Learning, Memory and Cognition, vol. 31, no. 1, 2005, pp. 3-8. 
Pica, Teresa. "Adult Acquisition of English as a Second Language Under Different Conditions of Exposure.” Language Learning, vol. 33, 1983, pp. 465-497.

Puren, Christian. Histoire des méthodologies de l'enseignement des langues. Paris, CLE international, 1988.

Quaireau, Christophe, et al. "Tacit-Ortho: un logiciel en ligne pour aider à comprendre l'implicite des textes." Communication orale, Les Entretiens de Bichat, Paris, 2016, pp. 1-7.

Roediger III, Henry L., and Elizabeth J. Marsh. "The Positive and Negative Consequences of Multiple-Choice Testing." Journal of Experimental Psychology: Learning, Memory and Cognition, vol. 31, no. 5, 2005, pp. 1155-1159.

Selinker, Larry. "Interlanguage." International Review of Applied Linguistics, vol. 10, 1972, pp. 219-231, doi : 10.1515/iral.1972.10.1-4.209.

Spada, Nina, and Yasuyo Tomita. "Interactions Between Type of Instruction and Type of Language Feature: A Meta-Analysis." Language Learning, vol. 60, no. 2, June 2010, pp. 263-308.

Truong, Huong May. "Integrating Learning Styles and Adaptive E-Learning System : Current Developments, Problems and Opportunities." Computers in Human Behavior, vol. 5, 2016, pp. 1185-1193.

U.S. Department of Education, Office of Planning, Evaluation, and Policy Development. Evaluation of Evidence-Based Practices in Online Learning : A Meta-Analysis and Review of Online Learning Studies. 2010, Washington, D.C., www2.ed.gov/rschstat/eval/tech/evidencebased-practices/finalreport.pdf. Accessed 18 Oct. 2018.

Van der Yeught, Michel. "Developing English for Specific Purposes (ESP) in Europe : Mainstream Approaches and Complementary Advances." Sub-plenary lecture, ESSE conference, Galway, Ireland, August 2016.

Vandewaetere, Mieke, et al. "The Contribution of Learner Characteristics in the Development of Computer-Based Adaptive Learning Environments." Computers in Human Behavior, vol. 27, 2011, pp. 118-130.

Vegada, Bhavisha, et al. "Comparison Between Three Option, Four Option and Five Option Multiple Choice Question Tests for Quality Parameters : A Randomized Study." Indian J Pharmacol, vol. 48, 2016, pp. 571-575.

Villessèche, Julie, et al. "Enhancing Reading Skills Through Adaptive E-Learning." Interactive Technology and Smart Education, vol.16, no. 1, 2018, pp. 2-17, doi : 10.1108/ITSE-07-2018-0047. 
Vygotski, Lev. Pensée et langage. Paris, Terrains/Éditions Sociales, 1985.

Widdowson, Henry. Defining Issues in Language English Teaching. Oxford, Oxford University Press, 2003.

Wright, Benjamin D., and Graham A. Douglas. "Best Test Design and Self-Tailored Testing." Research Memorandum, vol. 19, 1975, pp. 1-55.

Yang, Ya-Ting Carolyn, et al. "An Online Adaptive Learning Environment for CriticalThinking-Infused English Literacy Instruction." British Journal of Educational Technology, vol. 45, no. 4, 2014, pp. 723-747.

Zimmerman, Barry J. "Attaining Self-Regulation: A Social Cognitive Perspective." Handbook of Self-Regulation, edited by Boekaerts, Monique, et al., San Diego, CA, Academic Press, 2000, pp. 13-39, doi :10.1016/b978-012109890-2/50031-7. 